\title{
Relationship between retinal inner nuclear layer, age, and disease activity in progressive MS
}

Maria Cellerino, MD, Christian Cordano, MD, PhD, Giacomo Boffa, MD, Giulia Bommarito, MD, Maria Petracca, MD, PhD, Elvira Sbragia, MD, Giovanni Novi, MD, Caterina Lapucci, MD, Elisabetta Capello, MD, Antonio Uccelli, MD, and Matilde Inglese, MD, PhD

Neurol Neuroimmunol Neuroinflamm 2019;6:e596. doi:10.1212/NXI.0000000000000596

\section{Abstract}

\section{Objective}

To investigate whether inner nuclear layer (INL) thickness as assessed with optical coherence tomography differs between patients with progressive MS (P-MS) according to age and disease activity.

\section{Methods}

In this retrospective longitudinal analysis, differences in terms of peripapillary retinal nerve fiber layer (pRNFL), ganglion cell layer + inner plexiform layer (GCIPL), INL and T1/T2 lesion volumes (T1LV/T2LV) were assessed between 84 patients with P-MS and 36 sex- and agematched healthy controls (HCs) and between patients stratified according to age (cut-off: 51 years) and evidence of clinical/MRI activity in the previous 12 months

\section{Results}

pRNFL and GCIPL thickness were significantly lower in patients with P-MS than in HCs ( $p=$ 0.003 and $p<0.0001$, respectively). INL was significantly thicker in patients aged $<51$ years compared to the older ones and HCs (38.2 vs 36.5 and $36.7 \mu \mathrm{m} ; p=0.038$ and $p=0.04$, respectively) and in those who presented MRI activity (new T2/gadolinium-enhancing lesions) in the previous 12 months compared to the ones who did not and HCs (39.5 vs 36.4 and $36.7 \mu \mathrm{m} ; p=0.003$ and $p=0.008$, respectively). Recent MRI activity was significantly predicted by greater INL thickness (Nagelkerke $\mathrm{R}^{2} 0.36, p=0.001$ ).

\section{Conclusions}

INL thickness was higher in younger patients with P-MS with recent MRI activity, a criterion used in previous studies to identify a specific subset of patients with P-MS who best responded to disease-modifying treatment. If this finding is confirmed, we suggest that INL thickness might be a useful tool in stratification of patients with P-MS for current and experimental treatment choice.

\author{
Correspondence \\ Dr. Inglese \\ matilde.inglese@mssm.edu
}




\section{Glossary}

DMT $=$ disease-modifying treatment; EDSS $=$ Expanded Disability Status Scale; GCIPL $=$ ganglion cell layer + inner plexiform layer; $\mathbf{H C}=$ healthy control; INL = inner nuclear layer; $\mathbf{L V}=$ lesion volume; $\mathbf{M M E}=$ microcystic macular edema; $\mathbf{O C T}=$ optical coherence tomography; $\mathbf{O N}=$ optic neuritis; $\mathbf{P}-\mathbf{M S}$ = progressive MS; $\mathbf{P R N F L}=$ peripapillary retinal nerve fiber layer; $\mathbf{R R}=$ relapsing-remitting.

Optical coherence tomography (OCT) provides measures of the peripapillary retinal nerve fiber layer ( $\mathrm{pRNFL}$ ) and retinal layer volumes. The progressive thinning of pRNFL and ganglion cell layer + inner plexiform layer (GCIPL) is considered biomarkers of neurodegeneration in MS. ${ }^{1}$ Conversely, the thickness of inner nuclear layer (INL) has been recently proposed as a measure of inflammatory activity in patients with relapsingremitting MS (RR-MS). ${ }^{2,3}$ However, INL has not been extensively studied in patients with progressive MS (P-MS).

Phase III trials have shown that disease-modifying treatments (DMTs) are more efficacious in subgroups of progressive patients aged $<51$ years and with presence of gadolinium-enhancing lesions on MRI. ${ }^{4}$ Therefore, we sought to investigate whether INL thickness can reflect inflammation-related differences in patients with P-MS with different range of age and disease activity. A simple and cost-efficient retinal measure could help in identifying patients with P-MS who may benefit from DMTs.

The aims of our study were to (1) characterize INL in patients with P-MS and (2) investigate whether INL thickness differs between patients with P-MS stratified according to age and evidence of disease activity.

\section{Methods}

\section{Study design}

In this retrospective longitudinal cohort study, 90 patients suffering from P-MS and 36 sex- and age-matched healthy controls (HCs) were recruited from 2 MS centers between 2014 and 2018 (64 patients and 16 HCs from San MartinoIST Hospital, Genova, Italy; 26 patients and $20 \mathrm{HCs}$ from Icahn School of Medicine at Mount Sinai, NY). Inclusion criteria were (1) age 18-80 years, (2) MS diagnosis according to the $2010 \mathrm{McDonald}$ 's criteria, ${ }^{5}$ and (3) progressive course according to Lublin's criteria. ${ }^{6}$ If treated, patients needed to be stable on their DMT for at least 1 year. Exclusion criteria were (1) substantial ophthalmologic pathologies (including iatrogenic optic neuropathy/diabetes/uncontrolled hypertension), (2) refractive errors $\pm 6 \mathrm{D}$, and (3) previous (any time during disease course) bilateral optic neuritis (ON). In patients with previous unilateral $\mathrm{ON}$, only the nonaffected eye was analyzed ( $n=6$, none occurring during the previous 12 months). In patients without history of ON and HC, OCT metrics were averaged over the 2 eyes.

All subjects underwent (1) assessment of the Expanded Disability Status Scale (EDSS) score and (2) standardized spectral
domain-OCT protocols (Spectralis, Heidelberg-Engineering), performed and processed by a single certified neurologist as previously described, ${ }^{7}$ in accordance with the APOSTEL recommendations $^{8}$ (details available on request). Global-pRNFL, GCIPL, and INL thickness were measured (Heidelberg Eye Explorer mapping software version 6.0.9.0.). Scans violating international-consensus quality-control criteria (OSCAR-IB) were excluded ( $\mathrm{n}=6$ patients excluded due to poor OCT quality; $\mathrm{n}=84$ patients entered the final analysis); (3) MRI using $1.5 \mathrm{~T}$ (Avanto, Siemens Healthcare) $(\mathrm{n}=27)$ or $3 \mathrm{~T}$ (Philips Achieva) $(\mathrm{n}=57)$ scanner. Axial spin-echo 2D T2-weighted (3-mm thick continuous slices covering the entire brain) and 3D T1-weighted $\left(1 \mathrm{~mm}^{3}\right.$ isotropic) sequences were standardized between centers. $\mathrm{T} 2 / \mathrm{T} 1$ lesion volumes (T2LV/T1LV) were measured (Jim version 7.0; XInapse Systems Ltd, United Kingdom) by an experienced operator blinded to subjects' identities.

To assess clinical/MRI activity in the year prior to enrollment, we retrospectively revised patients' charts and collected the number of clinical relapses/EDSS score in the previous 12 months and of new T2/gadolinium-enhancing lesions with respect to a clinical MRI performed 12 months earlier (MRI data available for $\mathrm{n}=77$ patients).

Patients were stratified according to (1) age ( $>$ or $<51$-yearsold) ${ }^{4}$; (2) evidence of disease activity (presence of at least one of (a) clinical activity: occurrence of $\geq 1$ relapses and/or 1 EDSS point increase or 0.5 if baseline EDSS $\geq 5.5$; or (b) MRI activity: new $\mathrm{T} 2$-and/or gadolinium-enhancing lesions) in the previous 12 months.

\section{Statistics}

Analyses were performed using SPSS 22.0 (IBM; X). Demographic and T1LV/T2LV differences between groups were analyzed using $\chi^{2}$, Mann-Whitney/Kruskal-Wallis, and independent-samples $t$ tests where appropriate. For OCTderived measures, we used analysis of covariance. Patients vs controls analyses were adjusted for age and gender; agerelated subgroup analyses $(n=84)$ were adjusted for gender, disease duration, treatment, and MRI scanner; for clinical/ MRI activity-related subgroup analyses, we added age to the covariates listed above. The relationships of OCT metrics with T1LV/T2LV and MRI activity in the previous 12 months were assessed with Spearman correlation and logistic regression analysis (adjusted for gender, age, disease duration, treatment, and MRI scanner), respectively. All $p$ values were 2 -sided and considered statistically significant when $p \leq 0.05$. Since our study is exploratory, we did not adjust for multiple comparisons. 
Standard protocol approvals, registrations, and patient consents

The study was approved by the local ethical committees and written informed consent was obtained from all participants according to the Declaration of Helsinki.

Table 1 Demographics, clinical, OCT, and MRI variables of global PMS population and controls

\begin{tabular}{|c|c|c|c|}
\hline & PMS $(n=84)$ & HCs $(n=36)$ & $p$ Values $^{\mathrm{a}}$ \\
\hline \multicolumn{4}{|l|}{ Demographics } \\
\hline $\begin{array}{l}\text { Age, mean } \\
\text { (SD)-median } \\
\text { (range), y }\end{array}$ & $\begin{array}{l}50.3(11)-51 \\
(22-79)\end{array}$ & $\begin{array}{l}51.1(15)-54 \\
(25-74)\end{array}$ & 0.77 \\
\hline Female, no. (\%) & $42(50 \%)$ & $18(50 \%)$ & 0.57 \\
\hline $\begin{array}{l}\text { Disease duration, } \\
\text { mean (SD), y }\end{array}$ & $12.3(8.7)$ & - & - \\
\hline PPMS, no (\%) & $62(74 \%)$ & - & - \\
\hline $\begin{array}{l}\text { Treated patients, } \\
\text { no. (\%) }\end{array}$ & $51(61 \%)$ & - & - \\
\hline Interferon & $3(4 \%)$ & & \\
\hline Glatiramer acetate & $12(14 \%)$ & & \\
\hline Dimethyl fumarate & $2(2 \%)$ & & \\
\hline Teriflunomide & $1(1 \%)$ & & \\
\hline Fingolimod & $6(7 \%)$ & & \\
\hline Natalizumab & $2(3 \%)$ & & \\
\hline Alemtuzumab & $2(3 \%)$ & & \\
\hline Cyclophosphamide & $1(1 \%)$ & & \\
\hline Rituximab & $5(6 \%)$ & & \\
\hline Ocrelizumab & $16(19 \%)$ & & \\
\hline HSCT & $1(1 \%)$ & & \\
\hline $\begin{array}{l}\text { EDSS score, median } \\
\text { (range) }\end{array}$ & $5.5(2-7.5)$ & - & \\
\hline \multicolumn{4}{|l|}{ OCT and MRI } \\
\hline pRNFL, mean (SD) & $90.1(8.7)$ & $97.2(11.7)$ & 0.003 \\
\hline GCIPL, mean (SD) & $76.5(12.1)$ & $86.1(8.6)$ & $<0.0001$ \\
\hline INL, mean (SD) & $37.4(3.5)$ & $36.7(0.5)$ & 0.29 \\
\hline T2LV, mean (SD) & $15.52(18.5)$ & - & - \\
\hline T1LV, mean (SD) & $7.58(10.2)$ & - & - \\
\hline
\end{tabular}

Abbreviations: EDSS = expanded disability status scale; GCIPL = ganglion cell layer + inner plexiform layer; $\mathrm{HC}=$ healthy control; $\mathrm{HSCT}=$ hematopoietic stem cell transplantation; INL = inner nuclear layer; PMS = progressive MS; PPMS = primary progressive MS; PRNFL = peripapillary retinal nerve fiber layer; T1LV = T1-weighted lesion volume; T2LV = T2weighted lesion volume.

OCT metrics (thickness) are expressed in microns; T2- and T1-weighted lesion volumes are expressed in milliliters.

Significant difference between the 2 groups are reported in bold.

a $p$ Values for the MS vs HC comparison; independent-samples $t$ test (age), $\chi^{2}$ (gender), ANCOVA adjusted for age and gender (OCT measures).

\section{Data availability}

Raw data are available upon appropriate request.

\section{Results}

Demographic, clinical, OCT, and MRI data regarding 84 patients with P-MS (62 primary P-MS, 22 secondary P-MS) and $36 \mathrm{HCs}$ are reported in table 1 . No one presented microcystic macular edema (MME). Patients showed a significantly reduced pRNFL $(-7.1 \pm 2.3 \mu \mathrm{m}, p=0.003)$ and GCIPL $(-9.6 \pm 2.2 \mu \mathrm{m}, p<0.0001)$ thickness compared to HCs; no significant differences emerged in terms of INL. No significant correlations were found between T1LV/T2LV and pRNFL $(p=0.8 / p=0.9$, respectively), GCIPL $(p=0.1 / p=$ 0.3 , respectively), and INL $(p=0.3 / p=0.06$, respectively).

Subgroup analysis are reported in table 2 (age-related stratification) and table 3 (clinical/MRI activity-related stratification) and shown in figure e-1 (links.lww.com/NXI/A138). Patients aged $<51$ years had significantly thicker INL than the older ones and HCs (38.2 vs 36.5 and $36.7 \mu \mathrm{m} ; p=0.038$ and $p=$ 0.04 , respectively). As expected, ${ }^{10}$ no age-related INL differences emerged in HC. INL was thicker in patients who showed disease activity in the previous 12 months $(38.05 \mu \mathrm{m})$ compared to the ones who did not $(36.2 \mu \mathrm{m})$, but such difference did not reach significance $(p=0.1)$. Accordingly, we stratified patients separately considering clinical (relapses/progression) or MRI activity. A thicker INL was observed in patients who showed MRI activity in the previous 12 months compared to those who did not and controls (39.5 vs 36.4 and $36.7 \mu \mathrm{m} ; p=$ 0.003 and $p=0.008$, respectively). The mean differences in OCT-derived metrics and $95 \% \mathrm{CI}$ for all comparisons are reported in table e-1 (links.lww.com/NXI/A139).

Logistic regression models testing INL as a predictor of MRI activity in the previous 12 months explained $35 \%$ of variance in the outcome (Nagelkerke $\mathrm{R}^{2} 0.36, p=0.001$ ); the inclusion of pRNFL and GCIPL did not improve prediction of the model (Nagelkerke $\mathrm{R}^{2} 0.37, p=0.004$ ), as INL remained the only significant contributor to the equation ( $\mathrm{pRNFL} p=0.47$; GCIPL $p=0.49$; INL $p=0.009$ ).

\section{Discussion}

Our results confirm that despite reduced pRNFL and GCIPL thickness, ${ }^{1,7}$ no significant differences emerged in terms of INL in P-MS compared to controls. ${ }^{2}$ However, when we stratified patients according to age and MRI activity, INL was significantly thicker in patients with P-MS aged $<51$ years and those with recent T2-/gadolinium-enhancing lesions. Furthermore, even accounting for age, INL was able to significantly classify patients with P-MS according to recent MRI activity. Different possible mechanisms involved in INL thickening in MS have been proposed, including the presence of MME, inflammationrelated dynamic fluid shifts, noninflammation-related traction following RNFL/GCIPL atrophy. ${ }^{2,3}$ We did not observe MME 
Table 2 Demographics, clinical, OCT, and MRI variables of age-related subgroup analysis

\begin{tabular}{|c|c|c|c|c|c|c|}
\hline & Patients $<51$ y $(n=43)$ & Patients $>51$ y $(n=41)$ & $p$ Values $^{a}$ & HCs $(n=36)$ & $p$ Values $^{b}$ & $p$ Values $^{c}$ \\
\hline \multicolumn{7}{|l|}{ Demographics } \\
\hline $\begin{array}{l}\text { Age, mean (SD)-median } \\
\text { (range), y }\end{array}$ & $41.8(7)-43(22-50)$ & $59.2(6)-59(51-79)$ & $<0.0001$ & $51.1(15)-54(25-74)$ & 0.001 & 0.002 \\
\hline Female, no. (\%) & $19(44 \%)$ & $23(56 \%)$ & 0.2 & $18(50 \%)$ & 0.6 & 0.6 \\
\hline Disease duration, mean (SD), y & $9.9(6.5)$ & $14.9(10.04)$ & 0.049 & - & - & - \\
\hline PPMS, no. (\%) & $32(74 \%)$ & $30(73 \%)$ & 0.5 & - & - & - \\
\hline Treated patients, no. (\%) & $36(83 \%)$ & $15(36 \%)$ & $<0.0001$ & - & - & - \\
\hline EDSS score, median (range) & $6(2-7)$ & $5.5(2.5-7.5)$ & 0.7 & - & - & - \\
\hline \multicolumn{7}{|l|}{ OCT and MRI } \\
\hline pRNFL, mean (SD) & $91.8(11.2)$ & $88.2(12.7)$ & 0.9 & $97.2(11.7)$ & 0.2 & 0.004 \\
\hline GCIPL, mean (SD) & $78.3(11.9)$ & $74.7(12.1)$ & 0.6 & $86.1(8.6)$ & 0.004 & $<0.0001$ \\
\hline INL, mean (SD) & $38.2(3.8)$ & $36.5(3.0)$ & 0.038 & $36.7(0.5)$ & 0.04 & 0.4 \\
\hline T2LV, mean (SD) & $15.86(20.3)$ & $15.17(16.6)$ & 0.8 & - & - & - \\
\hline \multirow[t]{2}{*}{ T1LV, mean (SD) } & $6.76(9.4)$ & $8.44(11.0)$ & 0.8 & - & - & - \\
\hline & \multicolumn{2}{|c|}{ HCs < 51y $(n=14)$} & \multicolumn{2}{|c|}{ HCs > 51y $(n=22)$} & & $P$ Values ${ }^{d}$ \\
\hline \multicolumn{7}{|l|}{ Demographics } \\
\hline \multicolumn{2}{|c|}{ Age, mean (SD)-median (range), y } & $35.3(8)-35(24-50)$ & \multicolumn{2}{|c|}{$61.2(7)-61(51-73)$} & & $<0.0001$ \\
\hline Female, no. (\%) & & $6(43 \%)$ & \multicolumn{2}{|c|}{$12(54 \%)$} & & 0.5 \\
\hline \multicolumn{7}{|l|}{ OCT } \\
\hline pRNFL, mean (SD) & \multicolumn{2}{|c|}{$98.2(10.7)$} & \multicolumn{2}{|c|}{$96.5(12.5)$} & & 0.6 \\
\hline GCIPL, mean (SD) & \multicolumn{2}{|c|}{$89.2(7.6)$} & \multicolumn{2}{|c|}{$84.1(8.8)$} & & 0.09 \\
\hline INL, mean (SD) & \multicolumn{2}{|c|}{$35.9(4.4)$} & \multicolumn{2}{|c|}{$37.1(3.4)$} & & 0.3 \\
\hline
\end{tabular}

Abbreviations: EDSS = expanded disability status scale; GCIPL = ganglion cell layer + inner plexiform layer; $\mathrm{HC}=$ healthy control; INL = inner nuclear layer; PPMS = primary progressive MS; pRNFL = peripapillary retinal nerve fiber layer; T1LV = T1-weighted lesion volume; T2LV = T2-weighted lesion volume. OCT metrics (thickness) are expressed in microns; T2 and T1-weighted lesion volumes are expressed in milliliters.

Significant difference between the 2 groups are reported in bold.

a $p$ Values for the comparison between patients <51-year-old vs those > 51-year-old; independent-samples $t$ test (age), $\chi^{2}$ (gender and phenotype), MannWhitney (disease duration, EDSS), Kruskal-Wallis (T1LV, T2LV), ANCOVA adjusted for gender, disease duration, treatment and MRI scanner (OCT measures).

${ }^{\mathrm{b}} p$ Values for patients <51-year-old vs $\mathrm{HC}$; independent-samples $t$ test (age), $\chi^{2}$ (gender), ANCOVA adjusted for gender and age (OCT measures).

c $p$ Values for patients >51-year-old vs HC; independent-samples $t$ test (age), $\chi^{2}$ (gender), ANCOVA adjusted for gender and age (OCT measures).

a $p$ Values for patients <51-year-old vs > 51-year-old HC comparison; independent-samples $t$ test (age), $\chi^{2}$ (gender), ANCOVA adjusted for gender (OCT measures).

or statistically significantly lower GCIPL/pRNFL thickness in those subgroups of patients with thicker INL (aged $<51$ years and with recent MRI activity). Taken together, our results provide preliminary evidence supporting the role of INL as a marker of ongoing inflammatory processes, not only in RR$\mathrm{MS}^{3}$ but also in patients with P-MS. This is particularly promising given the paucity of validated outcome measures measuring disease activity in P-MS. The retrospective design, limited and unequal sample size of HCs and patients, inclusion of both primary- and secondary-P-MS subjects, and the absence of spinal cord activity data should be considered limitations of our study. Prospective and multicentric studies confirming our results are needed. This may lead to the identification of a cutoff to use in clinical practice and clinical trials to select patients with P-MS more likely to respond to therapy.

\section{Conclusions}

INL thickness was higher in younger patients with P-MS with higher/recent MRI activity, supposed to best benefit from treatment. If our finding is confirmed, INL might be considered a useful tool for the stratification of patients with P-MS for current and experimental treatment choice.

\section{Study funding}

The study was in part supported by the NMSS RG 5120-A-3 to MI.

\section{Disclosure}

M. Cellerino, C. Cordano, G. Boffa, G. Bommarito, M. Petracca, E. Sbragia, G. Novi, C. Lapucci, E. Capello report 


\begin{tabular}{|c|c|c|c|c|c|c|}
\hline & Clinical activity $(n=33)$ & No clinical activity $(n=44)$ & $p$ Values $^{a}$ & HCs $(n=36)$ & $p$ Values $^{b}$ & $p$ Values $^{c}$ \\
\hline \multicolumn{7}{|l|}{ Demographics } \\
\hline $\begin{array}{l}\text { Age, mean (SD)-median } \\
\text { (range), } y\end{array}$ & $45.3(10)-47(22-66)$ & $53.1(10)-55(34-68)$ & 0.001 & $51.1(15)-54(25-74)$ & 0.06 & 0.4 \\
\hline Female, no. (\%) & $16(48 \%)$ & 24 (54\%); & 0.6 & $18(50 \%)$ & 0.9 & 0.7 \\
\hline Disease duration, mean (SD), y & $11.6(10.1)$ & $13.1(8.1)$ & 0.4 & - & - & - \\
\hline PPMS, no (\%) & $21(63.6 \%)$ & 35 (79.5\%) & 0.1 & - & - & - \\
\hline Treated patients, no. (\%) & $25(76 \%)$ & $25(57 \%)$ & 0.001 & - & - & - \\
\hline EDSS score, median (range) & $5.5(2-7.5)$ & $5(2-7)$ & 0.08 & - & - & - \\
\hline \multicolumn{7}{|l|}{ OCT and MRI } \\
\hline pRNFL, mean (SD) & $91.1(12.3)$ & $89.2(12.4)$ & 0.5 & $97.2(11.7)$ & 0.03 & 0.007 \\
\hline INL, mean (SD) & $37.7(3.6)$ & $36.8(3.2)$ & 0.7 & $36.7(0.5)$ & 0.2 & 0.7 \\
\hline T2LV, mean (SD) & $20.3(21.1)$ & $12.7(15.9)$ & 0.8 & - & - & - \\
\hline \multirow[t]{2}{*}{ T1LV, mean (SD) } & $9.2(10.5)$ & $6.5(10.7)$ & 0.6 & - & - & - \\
\hline & MRI activity $(n=20)$ & No MRI activity $(n=57)$ & $p$ Values ${ }^{d}$ & HCs $(n=36)$ & $p$ Values $^{\mathbf{e}}$ & $p$ Values $^{f}$ \\
\hline \multicolumn{7}{|l|}{ Demographics } \\
\hline Age, mean (SD)-median (range), y & $43.9(10)-43(22-65)$ & $52.1(10)-53(22-68)$ & 0.003 & $51.1(15)-54(25-74)$ & 0.06 & 0.7 \\
\hline Female, no. (\%) & $9(45 \%)$ & $31(54 \%)$ & 0.4 & $18(50 \%)$ & 0.7 & 0.7 \\
\hline Disease duration, mean (SD), y & $10.8(7.1)$ & $13.2(9.5)$ & 0.3 & - & - & - \\
\hline PPMS, no (\%) & $14(70 \%)$ & $42(73.7 \%)$ & 0.7 & - & - & - \\
\hline Treated patients, no. (\%) & $17(85 \%)$ & $33(58 \%)$ & 0.03 & - & - & - \\
\hline EDSS score, median (range) & $5(2-7.5)$ & $5(2.5-7)$ & 0.9 & & & \\
\hline \multicolumn{7}{|l|}{ OCT and MRI } \\
\hline pRNFL, mean (SD) & $91.0(12.8)$ & $89.7(12.3)$ & 0.8 & $97.2(11.7)$ & 0.1 & 0.004 \\
\hline GCIPL, mean (SD) & $78.4(12.4)$ & $75.0(12.0)$ & 0.4 & $86.1(8.6)$ & 0.006 & $<0.0001$ \\
\hline INL, mean (SD) & $39.5(3.9)$ & $36.4(2.9)$ & 0.003 & $36.7(0.5)$ & 0.008 & 0.8 \\
\hline
\end{tabular}


Table 3 Demographics, clinical, OCT, and MRI variables subgroup analysis according to clinical/MRI activity during the previous 12 months (continued)

\begin{tabular}{|c|c|c|c|c|c|c|}
\hline & MRI activity $(n=20)$ & No MRI activity $(n=57)$ & $p$ Values $^{d}$ & HCs $(n=36)$ & $p$ Values $^{\mathbf{e}}$ & $p$ Values $^{f}$ \\
\hline T2LV, mean (SD) & $14.9(15.1)$ & $16.4(19.8)$ & 0.07 & - & - & - \\
\hline T1LV, mean (SD) & $4.99(5.1)$ & $8.72(11.2)$ & 0.08 & - & - & - \\
\hline
\end{tabular}

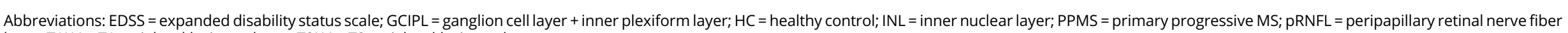
layer; T1LV = T1-weighted lesion volume; T2LV = T2-weighted lesion volume.

Clinical activity: presence of at least one of the following: (1) occurrence of relapses and (2) evidence of disease progression (defined as 1 EDSS point increase or 0.5 if baseline EDSS $\geq 5.5$ ).

MRI activity: evidence of new $T 2$ and/or gadolinium enhancing lesions.

OCT metrics (thickness) are expressed in microns; T2- and T1-weighted lesion volumes are expressed in milliliters.

Significant difference between the 2 groups are reported in bold.

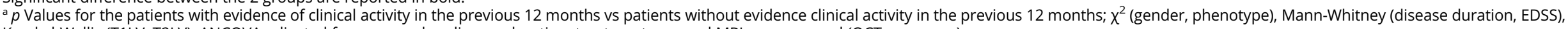
Kruskal-Wallis (T1LV, T2LV), ANCOVA adjusted for age, gender, disease duration, treatment use, and MRI scanner used (OCT measures).

${ }^{\mathrm{b}} p$ Values for the patients with evidence of clinical activity in the previous 12 months vs HCs; independent-samples $t$ test (age), $\chi^{2}$ (gender), ANCOVA adjusted for gender and age (OCT measures).

c $p$ Values for the patients without evidence clinical activity in the previous 12 months vs HC; independent-samples $t$ test (age), $\chi^{2}$ (gender), ANCOVA adjusted for gender and age (OCT measures).

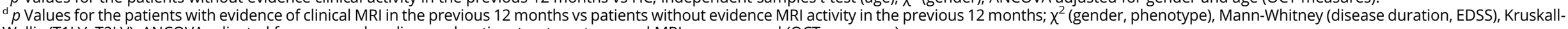
Wallis (T1LV, T2LV), ANCOVA adjusted for age, gender, disease duration, treatment use and MRI scanner used (OCT measures).

e $p$ Values for the patients with evidence of MRI activity in the previous 12 months vs HCs; independent-samples $t$ test (age), $\chi^{2}$ (gender), ANCOVA adjusted for gender and age (OCT measures).

${ }^{f} p$ Values for the patients without evidence MRI activity in the previous 12 months vs HCs; independent-samples $t$ test (age), $\chi^{2}$ (gender), ANCOVA adjusted for gender and age (OCT measures).

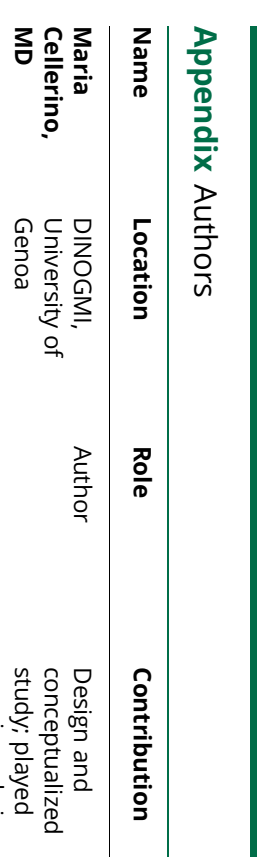




\section{Appendix (continued)}

\begin{tabular}{|c|c|c|c|}
\hline Name & Location & Role & Contribution \\
\hline $\begin{array}{l}\text { Matilde } \\
\text { Inglese, MD, } \\
\text { PhD }\end{array}$ & $\begin{array}{l}\text { DINOGMI, } \\
\text { University of } \\
\text { Genoa; Icahn } \\
\text { School of } \\
\text { Medicine, Mount } \\
\text { Sinai, NY }\end{array}$ & $\begin{array}{l}\text { Author } \\
\text { (Corresponding } \\
\text { author) }\end{array}$ & $\begin{array}{l}\text { Designed and } \\
\text { conceptualized } \\
\text { the study; and } \\
\text { revised the } \\
\text { manuscript for } \\
\text { intellectual } \\
\text { content }\end{array}$ \\
\hline
\end{tabular}

\section{References}

1. Petzold A, Balcer LJ, Calabresi PA, et al. Retinal layer segmentation in multiple sclerosis: a systematic review and meta-analysis. Lancet Neurol 2017;16:797-812.

2. Saidha S, Sotirchos ES, Ibrahim MA, et al. Microcystic macular oedema, thickness of the inner nuclear layer of the retina, and disease characteristics in multiple sclerosis: a retrospective study. Lancet Neurol 2012;11:963-972.
3. Knier B, Schmidt P, Aly L, et al. Retinal inner nuclear layer volume reflects response to immunotherapy in multiple sclerosis. Brain 2016;139:2855-2863.

4. Hawker K, O'Connor P, Freedman MS, et al. Rituximab in patients with primary progressive multiple sclerosis: results of a randomized double-blind placebocontrolled multicenter trial. Ann Neurol 2009;66:460-471.

5. Polman $\mathrm{CH}$, Reingold SC, Banwell B, et al. Diagnostic criteria for multiple sclerosis: 2010 Revisions to the McDonald criteria. Ann Neurol 2011;69:292-302.

6. Lublin FD, Reingold SC, Cohen J et al. Defining the clinical course of multiple sclerosis: the 2013 revisions. Neurology 2014;83:278-286.

7. Petracca M, Cordano C, Cellerino $\mathrm{M}$, et al. Retinal degeneration in primaryprogressive multiple sclerosis: a role for cortical lesions? Mult Scler J 2017;23: 43-50.

8. Cruz-Herranz A, Balk LJ, Oberwahrenbrock T, et al. IMSVISUAL consortium. The APOSTEL recommendations for reporting quantitative optical coherence tomography studies. Neurology 2016;86:2303-2309.

9. Schippling S, Balk LJ, Costello F, et al. Quality control for retinal OCT in multiple sclerosis: validation of the OSCAR-IB criteria. Mult Scler J 2015;21: 163-170.

10. Demirkaya N, van Dijk HW, van Shuppen SM, et al. Effect of age on individual retinal layer thickness in normal eyes as measured with spectral-domain ocptical coherence tomography. Invest Ophtalmol Vis Sci 2013;54:4934-4940. 


\title{
Neurology \\ Neuroimmunology \& Neuroinflammation
}

\author{
Relationship between retinal inner nuclear layer, age, and disease activity in \\ progressive MS \\ Maria Cellerino, Christian Cordano, Giacomo Boffa, et al. \\ Neurol Neuroimmunol Neuroinflamm 2019;6; \\ DOI 10.1212/NXI.0000000000000596
}

This information is current as of August 12, 2019

\section{Updated Information \& \\ Services}

References

Citations

Subspecialty Collections

Permissions \& Licensing

Reprints including high resolution figures, can be found at:

http://nn.neurology.org/content/6/5/e596.full.html

This article cites 10 articles, 1 of which you can access for free at: http://nn.neurology.org/content/6/5/e596.full.html\#\#ref-list-1

This article has been cited by 2 HighWire-hosted articles: http://nn.neurology.org/content/6/5/e596.full.html\#\#otherarticles

This article, along with others on similar topics, appears in the following collection(s):

Multiple sclerosis

http://nn.neurology.org//cgi/collection/multiple_sclerosis

Optic nerve

http://nn.neurology.org//cgi/collection/optic_nerve

Retina

http://nn.neurology.org//cgi/collection/retina

Information about reproducing this article in parts (figures,tables) or in its entirety can be found online at:

http://nn.neurology.org/misc/about.xhtml\#permissions

Information about ordering reprints can be found online:

http://nn.neurology.org/misc/addir.xhtml\#reprintsus

Neurol Neuroimmunol Neuroinflamm is an official journal of the American Academy of Neurology.

Published since April 2014, it is an open-access, online-only, continuous publication journal. Copyright

Copyright $\odot 2019$ The Author(s). Published by Wolters Kluwer Health, Inc. on behalf of the American

Academy of Neurology.. All rights reserved. Online ISSN: 2332-7812.

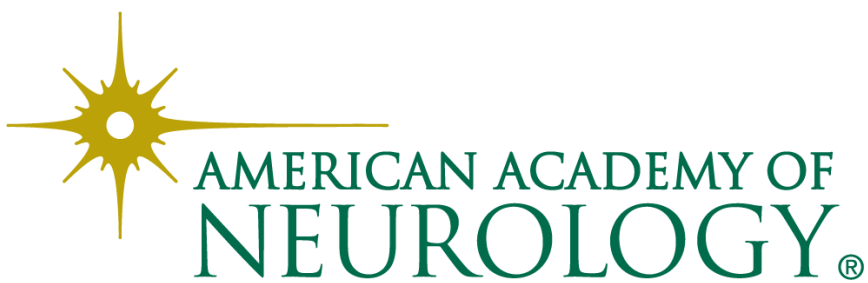

